\title{
Two Hundred Acres: First Draft of a Coroner's Report
}

In this town it can take almost eight hours to find a man in two hundred acres of trails and bare trees, even with clear footprints broken through the snow-

locals and relatives pulled out of bed, searching side by side with bleary-eyed constables, a visiting Red Cross worker, a plowman who couldn't get fuel on Christmas morning.

Understand that there is the thinly-iced creek to think about, winding through the bush, invisible under the drifts except by the evenness of snow and the lack of trees,

so much like the one our victim fell through to the left hip, the outing at that point still just a walk in the woods with the dog, every other track after that a limp-

and there's the trespassing hunters he tried to scare off, beer swilling and willing by dark to shoot at anything, it was they who shamefully lead investigators to where

his loaded .22 was found leaned against a tree, fingerprints torn off on the black metal of the barrel, the dog's tracks doubling back home from there-

and then there's those packs of small brush wolves yipping in the distance, attracted to the scent of failure, of sweat, of cold kidneys, of swatches of frozen piss

come out as yellow slush and ice pellets spread over the snow, red flakes of a urethra's blood spilled in patterns suggesting hypothermia- 
also, don't forget the caliginous cedars with raised roots and boughs, how they can slow a search, or how the supple branchlets of deciduous trees can slip into ear canals,

like the one that punched a circle in his tympanic membrane, left him breathless and bewildered, lying calmly in a drift as though in a deep featherbed.

But, all excuses aside, most of this short day was wasted battling the mind of winter, everyone suspecting shamefully within minutes it was the body they looked for, not the man, knowing everything before the report would be perfunctorya brief shot at resuscitation, a swathing of black limbs, another attempt at trudging home in the snow to join a wife in bed. 